\title{
EFFICIENT AND SAFE SUBSTRATES FOR BLACK SOLDIER FLY BIOWASTE TREATMENT ALONG CIRCULAR ECONOMY PRINCIPLES
}

\author{
Moritz Gold ${ }^{1,2, \star}$, Davis Ireri ${ }^{3}$, Christian Zurbrügg ${ }^{2}$, Trevor Fowles ${ }^{4}$ and Alexander Mathys ${ }^{1}$ \\ ${ }^{1}$ ETH Zurich, Sustainable Food Processing, Department of Health Science \& Technology, Institute of Food, Nutrition \& Health, Zurich, \\ Switzerland \\ 2 Eawag: Swiss Federal Institute of Aquatic Science and Technology, Department of Sanitation, Water and Solid Waste for Development \\ (Sandec), Dübendorf, Switzerland \\ ${ }^{3}$ Sanergy, New Technology Commercialization, Nairobi, Kenya \\ ${ }^{4}$ University of California, Department of Entomology and Nematology, Davis CA, USA
}

Article Info:

Received:

1 February 2021

Revised:

23.April 2021

Accepted:

31 May 2021

Available online:

30 September 2021

Keywords:

Hermetia illucens

Sustainability

Organic waste

Animal feed

Assessment

Waste recovery hierarchy

\section{ABSTRACT}

Black soldier fly larvae (BSFL) treatment is an emerging technology for the valorisation of nutrients from biowaste. Selecting suitable substrates for BSFL treatment is a frequent challenge for researchers and practitioners. We conducted a systematic assessment of BSFL treatment substrates in Nairobi, Kenya to source more substrate for upscaling an existing BSFL treatment facility. The applied approach is universal and considers four criteria: 1) substrate availability and costs, 2) BSFL process performance, 3 ) product safety, and 4) waste recovery hierarchy. Data were collected from previous waste assessments or semi-structured key informant interviews and sight tours of waste producers. Waste nutritional composition and BSFL process performance metrics were summarised in the "BSFL Substrate Explorer", an open-access web application that should facilitate the replication of such assessments. We show that most biowaste in Nairobi is currently not available for facility upscaling due to contamination with inorganics and a lack of affordable waste collection services. A mixture of human faeces, animal manure, fruit/vegetable waste, and food waste (with inorganics) should be pursued for upscaling. These wastes tend to have a lower treatment performance, but in contrast to cereal-based byproducts, food industry byproducts, and segregated food waste, there is no conflict with animal feed utilization. The traceability of substrates, source control, and post-harvest processing of larvae are required to ensure feed safety. The criteria presented here ensures the design of BSFL treatment facilities based on realistic performance estimates, the production of safe insect-based products, and environmental benefits of products compared to the status quo.

\section{INTRODUCTION}

Biowastes significantly contribute to the global waste problem (Gustavsson et al., 2011; Wilson et al., 2015). Currently, biowaste is frequently not safely managed, leading to the wastage of nutrients, energy, and water (Chen et al., 2020; Diener et al., 2014; Hoornweg \& Bhada-Tata, 2012). Biowaste management also contributes to global challenges, such as poor urban health, degradation of the natural environment, and climate change.

Black soldier fly larvae (BSFL) treatment is an emerging technology for biowaste treatment (Gold et al., 2018; Zurbrügg et al., 2018). The technology uses the immature life stage of the black soldier fly (Hermetia illucens, Diptera:
Stratiomyidae) that feeds on a large variety of biowastes and turns them into a compost-like residue (Gold et al., 2018). Insect biomass can be separated from the residue and processed into raw materials for various applications such as lubricants, biodiesel and pharmaceuticals, and currently most promising, for animal feed markets (Barragán-Fonseca et al., 2017; Bosch et al., 2014; Makkar et al., 2014), for example, dried larvae or protein meal as a feed ingredient for poultry, fish, pigs, and pets.

Throughout the past decades, research and implementation has indicated that the technology has the potential to produce higher treatment product revenues, result in reduced greenhouse gas emissions compared to other biowaste treatment technologies, such as composting, and 
produce insect-based feeds with a lower environmental impact than the status quo (Ermolaev et al., 2019; Gold et al., 2018; Mertenat et al., 2019; Smetana et al., 2019). In addition, the technology can operate at various scales, modularity, and levels of automation (Diener et al., 2011; Ites et al., 2020). These advantages have been demonstrated by the global industrial-scale implementation of BSFL technology in recent years, for example, the Netherlands, China, Chile, the USA, Germany, Kenya, South Africa, and Malaysia. However, to have a significant global impact on waste management and the sustainability of the food system, more insect-based biowaste treatment facilities are needed (Gold et al., 2018).

One main challenge faced by utilities, municipalities, insect companies, and entrepreneurs is the selection of suitable biowastes for BSFL treatment. Process performance as measured by bioconversion rate, and larval mass, and larval biomass composition, such as protein and lipid content, vary among substrates (Gold et al., 2018; Gold et al., 2020a; Lalander et al., 2019). In addition, chemical and microbial contaminants in different biowastes require careful consideration to ensure product safety (Van der Fels-Klerx et al., 2018). Moreover, substrates may already have a value when used in, for instance, animal feed and biogas production. Alternatively, the provision of the waste has high costs due to decentralised collection, long distances from the treatment facilitities, or high amounts of inorganic materials (plastic, glass, and paper) that need to be removed prior to BSFL treatment (Dortmans et al., 2017).

Here, we present a systematic approach to identify suitable substrates for BSFL treatment by considering waste availability and costs, the BSFL process performance of the biowaste, the waste recovery hierarchy, and product safety. The applied approach is universal and enables the design of BSFL treatment facilities based on realistic performance estimates, the production of safe insect-based products, and environmental benefits of products in comparison to the status quo. This study also developed the "BSFL Substrate Explorer", an open-access web application (moritzgold.shinyapps.io/BSF_app/) with tools to explore waste compositional data and BSFL process performance and formulate efficient biowaste mixtures.

\section{MATERIALS AND METHODS}

This case study was conducted in Nairobi, Kenya, using a combination of primary and secondary research. At the beginning of the assessment, approximately 20 tonnes/ day of human faeces and fruit and vegetable waste were treated at an existing BSFL treatment facility. The BSFL were processed into dry larvae and sold to feed millers, and the residue was composted and sold as a soil conditioner. The assessment was completed with the aim of sourcing more biowaste for the upscaling of the facility $(>100$ tonnes of waste per day).

\subsection{Selection criteria}

The biowaste assessment approach considered four criteria (Figure 1): waste availability and costs, the BSFL process performance of the biowaste, the waste recov- ery hierarchy, and product safety. These criteria can be processed step by step, either in parallel, or iteratively. The process performance of the biowaste is important because it influences the treatment time and larval and residue amounts produced per unit of biowaste. Ultimately, process performance influences operational costs and revenues from treatment products. Considering the waste recovery hierarchy as well as waste availability and potential waste costs is important because wastes with high process performances may already have uses, for example, as animal feed, and therefore, conversion of the waste may not produce affordable treatment products, or wastes may already be part of meaningful resource recovery (Smetana et al., 2019). Product safety is critical for BSFL treatment because treatment products are used for human food production, and wastes can include contaminants relevant to animal and human health (Van der FelsKlerx et al., 2018).

\subsection{Availability and costs}

Biowaste availability and the costs of wastes in Nairobi were assessed using criteria proposed by Lohri et al. (2015). These criteria include biowaste quantity, biowaste cost, waste characteristics (mixing of organics with inorganics), and the existing use of waste, for example, landfilling and composting. Biowaste quantities and costs were mainly assessed using previous waste assessments conducted in Nairobi (Baud et al., 2004; Njoroge et al., 2014; Kasozi \& Von Blottnitz, 2010; Kirai et al., 2009). Data were validated by semi-structured key informant interviews and sight tours of waste producers. These included restaurants and hotels, slaughterhouses, animal farms, supermarkets, and food industries.

\subsection{Process performance}

\subsubsection{Review of performance metrics}

The process performance of biowastes with BSFL was estimated using values provided in the literature of typical BSFL performance metrics, for example, larval mass, bioconversion rate, and waste reduction (Banks et al., 2014; Bava et al., 2019; Diener et al., 2009; Gold et al., 2021; Gold et al., 2020a; Jucker et al., 2017; Lalander et

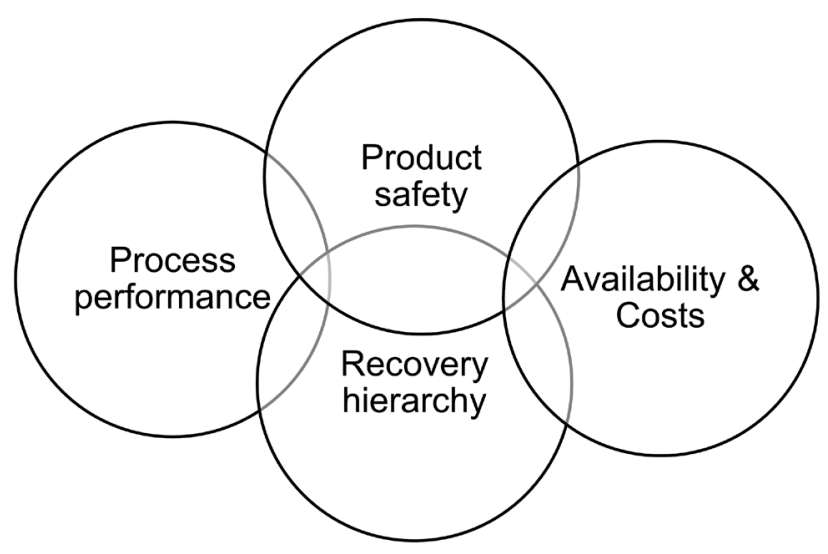

FIGURE 1: Criteria considered for selection of BSFL treatment substrate in Nairobi, Kenya. 
al., 2019; Liu et al., 2018; Meneguz et al., 2018; Miranda et al., 2019; Nguyen et al., 2013; Nyakeri et al., 2019; Rehman et al., 2017; Somroo et al., 2019; Spranghers et al., 2017; Tschirner \& Simon, 2015). The feeding rate and treatment time within these studies were $40-250 \mathrm{mg}$ waste/larva/ day and 6-27 days, respectively. Some wastes, including grass, wastewater sludge, or water hyacinths tended to be unsuitable for BSFL treatment because of very low growth (Dieu et al., 2015; Lalander et al., 2019; Liu et al., 2018) and were not included in the performance summary. Research to increase the growth of BSFL on these substrates by pre-treatments (Isibika et al., 2019) and co-conversion with beneficial bacteria (Mazza et al., 2020; Rehman et al., 2019) is ongoing.

\subsubsection{Biowaste analyses for mixture formulation}

A single biowaste stream cannot fulfil the entire treatment capacity (>100 tonnes/day); therefore, we analysed biowastes for gross nutrient composition. The formulation of biowaste mixtures based on similar nutrient content, especially protein and carbohydrates, has been tested as a promising approach for efficient and reliable BSFL treatment (Gold et al., 2020a; Barragán-Fonseca et al., 2018). Crude protein, lipids, neutral detergent fibre (NDF), acid detergent fibre (ADF), and ash were analysed using standard procedures used for animal feeds (Gold et al., 2020a). Protein was estimated by multiplying nitrogen with waste-specific factors (Chen et al., 2017; Mariotti et al., 2008; Sriperm et al., 2011). Hemicelluloses were determined as the difference between NDF and ADF. ADF was assumed to be a reliable estimate of the fibre (cellulose and lignin) content. Samples were pit latrine sludge $(n=3)$, human faeces with sawdust $(n=4)$, fruit and vegetable waste $(n=1)$, vegetable waste $(n=2)$, poultry feed $(n=1)$, food waste from hotels $(n=9)$, food waste from restaurants $(n=2)$, cereal-based by-products $(n=1)$, fruit waste $(n=4)$, and slaughterhouse waste $(n=2)$. To generalise our approach, values provided in the literature for the same parameters were summarised (Giromini et al., 2017; Gold et al. 2020a; Gold et al., 2020b; Gold et al., 2021; Liu et al., 2018; Meneguz et al., 2018; Shumo et al., 2019; Vruggink, 2020).

\subsubsection{Open-access web application}

Process performance and waste compositional data, as well as the formulation of biowaste mixtures, were included in an open-access web application called the "BSFL Substrate Explorer" (moritzgold.shinyapps.io/BSF_ app/). Process performance $(n=60)$ and biowaste compositional data $(n=67)$ were analysed using $R$ version 312 3.6.2 (R Core Team, 2020). Data were manipulated using tidyverse (Wickham et al., 2019) and were visualised by boxplots using ggplot2 (Wickham, 2016). In addition, compositional data were visualised in a two-dimensional plane following a principal component analysis (PCA) using the FactoMineR (Le et al., 2008) and factoextra package (Kassambara \& Mundt, 2020). The calculation of the nutrient content of biowaste mixtures was also included in the Shiny-based web application (Barragán-Fonseca et al., 2018; Gold et al., 2020a). These analyses were translated into the web application using the Shiny (Chang et al., 2020) and shinydashboard package (Chang \& Ribeiro, 2018). Shiny-based applications are interactive and change outputs, for example, plots and descriptive statistics, based on user input.

\subsection{Product safety}

Biowaste contains various contaminants such as microbes, for example, pathogenic bacteria and viruses, (heavy) metals, and/or chemicals, for example, pharmaceutical and pesticide residues (Gold et al., 2018; Van der Fels Klerx et al., 2018). We used the available BSFL literature, as well as general animal feed safety considerations of the Food and Agriculture Organization of the United Nations (FAO) (FAO, 1997) to identify potential waste contaminants in the identified wastes, their fate in BSFL treatment, and BSFL post-harvest processing.

\subsection{Waste recovery hierarchy}

BSFL treatment frequently aims to provide biowaste treatment and products with lower environmental impact than the status quo. Biowastes or byproducts with use as food or feed do typically do not provide environmental benefits in comparison to the status quo (Bosch et al., 2019; Smetana et al., 2016; Smetana et al., 2019). Using the waste recovery hierarchy concept (UNEP, 2013) and published life cycle assessments (LCAs) results (Bosch et al., 2019; Smetana et al., 2019), we discuss whether environmental benefits are likely to be associated with diverting the identified wastes to BSFL treatment. Even though results are very case specific (e.g. depending on substrate, energy type and production, post-processing of frass and larvae), typcial environmental benefits over production of conventional protein-rich feed ingredients and composting are lower greenhouse gas emissions and land use (Bosch et al., 2019; Mertenat et al., 2019).

\section{RESULTS AND DISCUSSION}

\subsection{Availability and costs}

In Nairobi, domestic and non-domestic biowaste is generated to upscale the BSFL treatment facility. Most biowaste in Nairobi is domestic, i.e., household waste. When considering the population (4.4 million, KEBS (2019)), the average city-wide waste generation estimate $(0.65 \mathrm{~kg} / \mathrm{cap}$ ita/day) and average waste composition (59\% of domestic waste is estimated to be organic), approximately 1,690 tons of household biowaste is generated per day (Kasozi \& Von Blottnitz, 2010). Determining the quanities of non-domestic biowaste, for example, from schools, restaurants, hotels, and markets, is more challenging because of an unknown number of sources $(>3,000)$ (Kirai et al., 2009) and variable waste generation rates per source (Table 1). Approximately $20-30 \%$ of all biowaste generated in the city has previously been estimated to be non-domestic using the estimate of total domestic waste generation (Kasozi \& Von Blottnitz, 2010; Kirai et al., 2009). Consequently, using the estimate for domestic waste generation and average waste compositon (74\% of waste is organic) (Kirai et al., 2009), approximately 529-906 tonnes of non-domestic biowaste is generated per day. Based on previous work by 
TABLE 1: Non-domestic waste generation (in $\mathrm{kg}$ ) per day and facility from different sources.

\begin{tabular}{|c|c|c|}
\hline Source & Waste examples & $\begin{array}{l}\text { Waste generation } \\
(\mathrm{kg} / \text { day })\end{array}$ \\
\hline Hotels & Food scraps & $200-2,000^{1,2}$ \\
\hline Restaurants & Food scraps & $2,100^{2}$ \\
\hline Markets & $\begin{array}{l}\text { Food scraps, discarded food } \\
\text { (e.g., fruit and vegetable peels) }\end{array}$ & $>19,000^{2}$ \\
\hline Shopping malls & Food scraps & $1,100^{2}$ \\
\hline $\begin{array}{l}\text { Commercial } \\
\text { animal farms }\end{array}$ & Pig and cow manure & $25,000^{2}$ \\
\hline Slaughterhouses & Blood, rumen content & $\begin{array}{l}45,000^{1} \\
16,000^{2}\end{array}$ \\
\hline Supermarkets & $\begin{array}{l}\text { Discarded fruits and vege- } \\
\text { tables }\end{array}$ & $2,500^{2}$ \\
\hline Food industry & $\begin{array}{l}\text { Discarded fruits and vegeta- } \\
\text { bles, byproducts from juice } \\
\text { production, canneries and } \\
\text { bread baking }\end{array}$ & $0.5-100^{1}$ \\
\hline
\end{tabular}

Kirai et al. (2009) and the interviews and field visits conducted in the present study, non-domestic biowaste in Nairobi consists of: fruit and vegetable wastes, for example, from canneries, juice producers, and retailers; animal manure, for example, dairy and pig farms; food waste, for example, retailers, markets, hotels, restaurants, and shopping malls; cereal-based byproducts, for example, spent grain from breweries, press cakes from oil production, byproducts from flour and animal feed mills, and slaughterhouse waste, for example, rumen content and blood. Solids in wastewater and faecal sludge are additional poorly managed and valorised wastes in Nairobi that could be poten- tially utilized as BSFL substrates.

\subsection{Process performance}

Figure 2 demonstrates the "Conversion performance" tab of the web application. It summarises the performance metrics of the BSFL treatment based on the substrate group and the performance metrics selected by the user. The summary can support the selection of efficient substrates and provides realistic performance estimates for treatment design (e.g., waste reduction) and estimations of treatment product quantities (e.g., bioconversion rate). Use of the web application shows that animal manure, faecal sludge, fruit and vegetable waste, and slaughterhouse waste, which are suitable for up-scaling based on availability and cost in Nairobi, typically result in lower larval weight and bioconversion rate than food waste, cereal-based byproducts, or human faeces.

The process performance of individual wastes is of limited value in Nairobi because a single waste stream cannot meet the entire treatment capacity (>100 tonnes/day). In this case, knowledge of an efficient biowaste mixture and the associated process performance is required. Typically, biowaste mixtures have been identified in trial and error feeding experiments with different biowaste mixtures (Nyakeri et al., 2019; Rehman et al., 2017). The formulation of biowaste mixtures based on nutritional composition, for example, overall nutrient content, protein, and carbohydrates, has recently emerged as a more systematic approach (Barragán-Fonseca et al., 2018; Gold, et al., 2020a). This approach considers that protein, digestible carbohydrates (a fraction of hemicelluloses), lipids, and the overall nutrient generally correlated with rearing performance. However, such an approach requires accurate waste com-
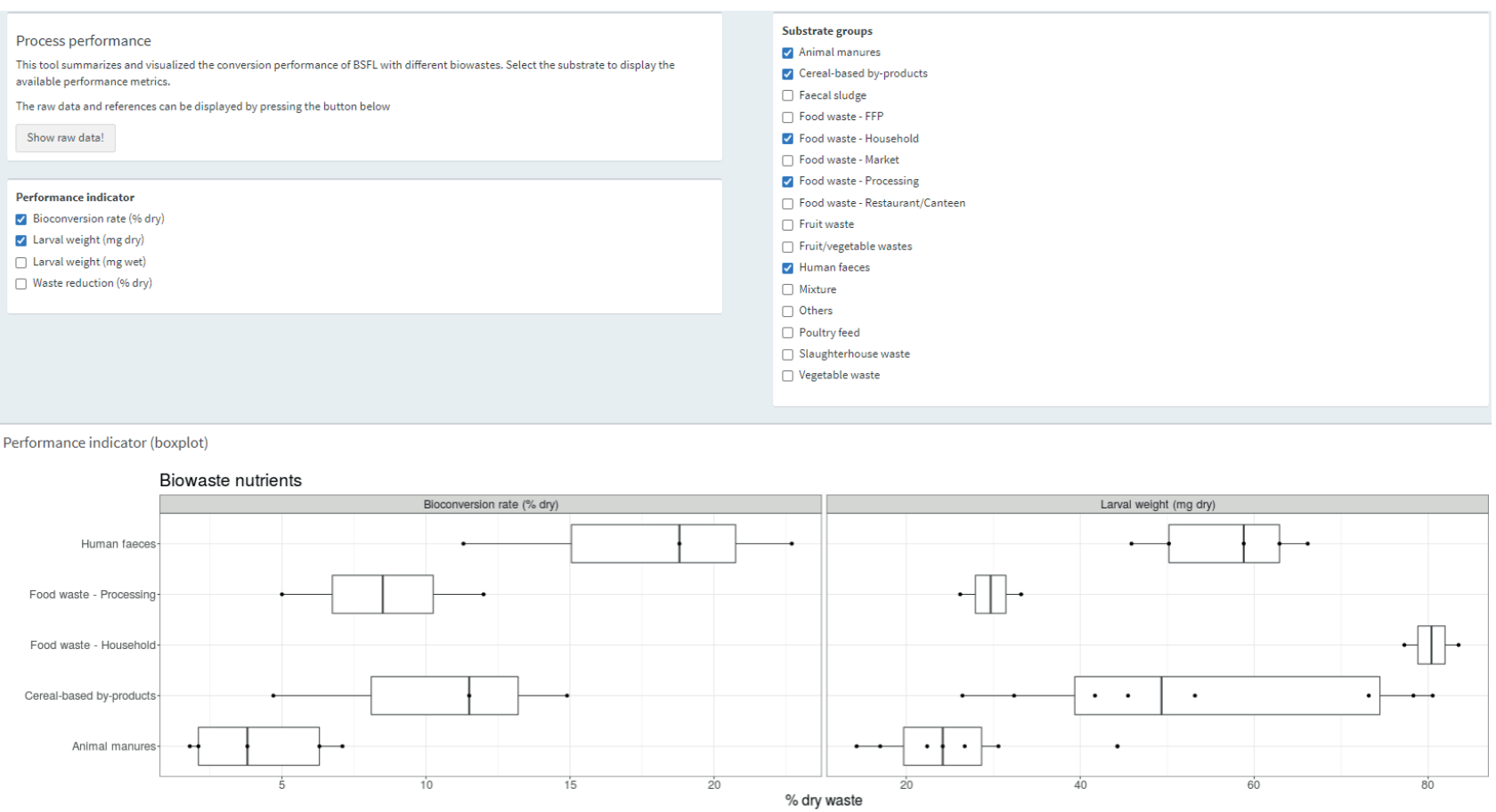

FIGURE 2: The "Conversion performance" tab of the web application summarises process performance results based on the substrate group and performance metric selected by the user. Descriptive statistics are included in a table below the boxplot (not shown in this Figure). 
positional data that are not always available.

Before the formulation of biowaste, it is helpful to gain a general understanding of the contents of important nutrients in the available wastes, such as protein, lipids, digestible carbohydrates (e.g. glucose and starch), hemicelluloses, fibres, and ash. Protein, lipids and digestible carbohydrates and potentially some fraction of hemicelluloses are thought to have a positive influence on process performance (Barragán-Fonseca et al., 2018; Gold et al., 2020a; Gold et al., 2018b). Fibres are important for substrate texture, but above yet unknown contents can decrease process performance (Liu et al., 2018). The substrate organic content ( $100 \%$ - ash) has also been shown to positively correlate with process performance (Lalander et al., 2019). The "Nutrient composition" tab of the web application (Figure 3) dynamically summarises and visualises the waste nutrient composition based on the BSFL substrate group (see Gold et al. (2018a)) and the nutrient parameters selected by the user. It shows a PCA biplot and summarises descriptive statistics in a table, for example, mean, standard deviation (sd), minimum (min), and maximum (max). The boxplots and PCA biplot demonstrated a large variability in nutrient composition among samples of the same substrate group. This is to be expected, because waste comes from different sources (e.g., different fruits or vegetables) and different waste management sys- tems (e.g., waste storage durations). Food wastes were the most variable because this substrate group includes former food stuffs (FFS), and waste from households, markets, canteens, and restaurants, which can differ greatly in nutrient composition. Despite this variability, the vector directions of the PCA biplot allow broad categories of waste based on nutrient composition. For example, considering the wastes available in Nairobi, animal manure and faecal sludge are high in fibres and low in lipids, and fruit and vegetable wastes are low in proteins and lipids. Despite its importancefor BSFL performance, no conclusions can be drawn on digestible carbohydrate contents in these substrates due to few or lacking results. Food waste is the substrate group with the highest nutrient content, and is typically high in proteins, lipids, digestible carbohydrates, and hemicelluloses, and low in ash and fibres. Consequently, to increase process performance, it could be beneficial to mix animal manure and faecal sludge with food waste. Information from compositional databases for food (ndb. nal.usda.gov), feed (feedipedia.org), and food wastes (foodwasteexplorer.eu) should also be considered beyond our web application.

Barragán-Fonseca et al. (2018) and Gold et al. (2020a) formulated biowaste mixtures using Microsoft Excel, without sharing the actual Excel tool. The "Substrate mixture formulation" tab (Figure 4) provides this calculation in a

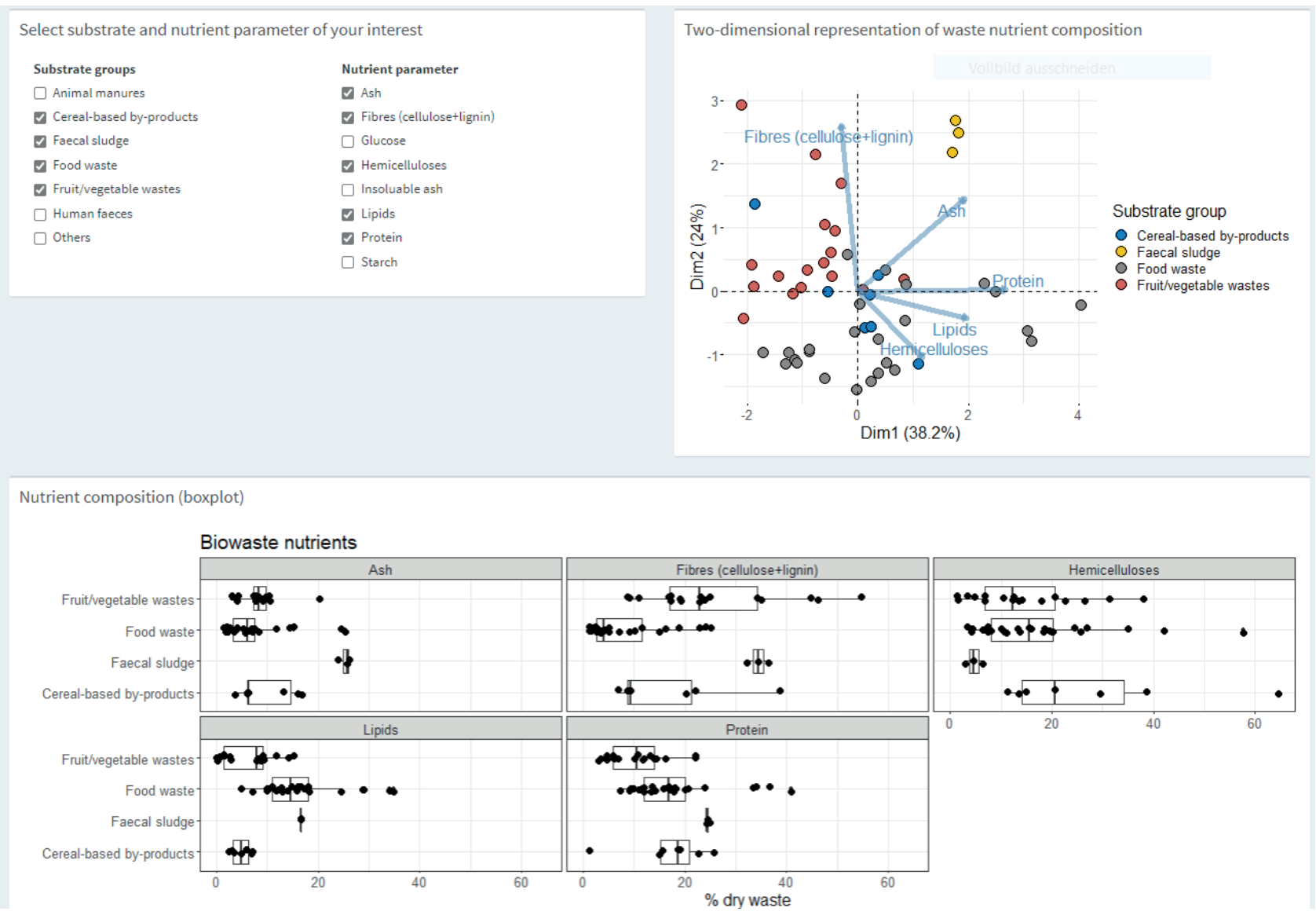

FIGURE 3: The "Nutrient composition" tab of the web application summarises the waste nutrient composition based on the substrate group and nutrient parameter selected by the user. Descriptive statistics are included in a table below the plots (not shown in this Figure). 
web application. It dynamically calculates the nutrient composition of biowaste mixtures (in wet and dry mass) based on the nutrient content of the individual wastes (Figure 3) with information on the quantity and moisture content of the wastes provided by the user. The web application considers the nutritional variability by displaying the range of the nutritional composition of the biowaste mixture, calculated with the minimum and maximum nutrient content for each ingredient. For the wastes ultimately selected for facility upscaling, this tool can be used to calculate the proportion of each waste that needs to be added to have similar nutrient content among batches. Balancing content among batches in these nutrients by mixing wastes can make the process performance more reliable. However, some variability will remain because the formulation relies on intrinsically variable waste compositional data (Figure 3). In addition, maintaining all macronutrients within fixed limits among batches is difficult in practice because wastes typically have variable amounts of each macronutrient.

\subsection{Product safety}

Table 2 summarises the potential hazards in the BSFL substrates identified in Nairobi. As BSFL live in their feeding substrate and the substrate passes through their digestive tract during feeding, substrate contaminants have a potential to accumulate on surfaces or be taken up with other digestion products into larval tissue (Gold et al., 2018a; Van der Fels Klerx et al., 2018). In addition, animal pathogens in substrates can populate the larval digestive tract. When considering the current knowledge on the fate of contaminants in BSFL treatment, heavy metals especially cadmium and arsenic in biowastes are a significant hazard for animal feed safety. In contrast to most microbes, for example, bacterial and viral pathogens that can be present in unprocessed BSFL but can be inactivated by heat treatment, some heavy metals have been shown to bioaccumulate in the larval tissue (Van der Fels Klerx et al., 2018; Diener et al., 2015; Schmitt et al., 2019). Spore-forming pathogens in substrates that are potentially transferred to the surface or digestive tracts of BSFL, such as Bacillus cereus and Clostridium botulinum, are also of special concern because they can survive heat treatment. Aflatoxin B1 (a common mycotoxin) and human/veterinary drugs and chemsporeicals have so far not been detected in BSFL grown on contaminated substrates (Bosch et al., 2017; Charlton et al., 2015; Lalander et al., 2016; Purschke et al., 2017). Hydrocarbons, for example, mineral oil hydrocarbons, dioxins, polychlorinated biphenyls (PCBs), and traces of plastic in substrates can accumulate following processing by BSFL in the larval tissue. However, concentrations of these contaminants were below legal limits at moderate substrate contaminant levels, for example, 3-6\% plastic fragments (van der Fels-Klerx et al., 2020).

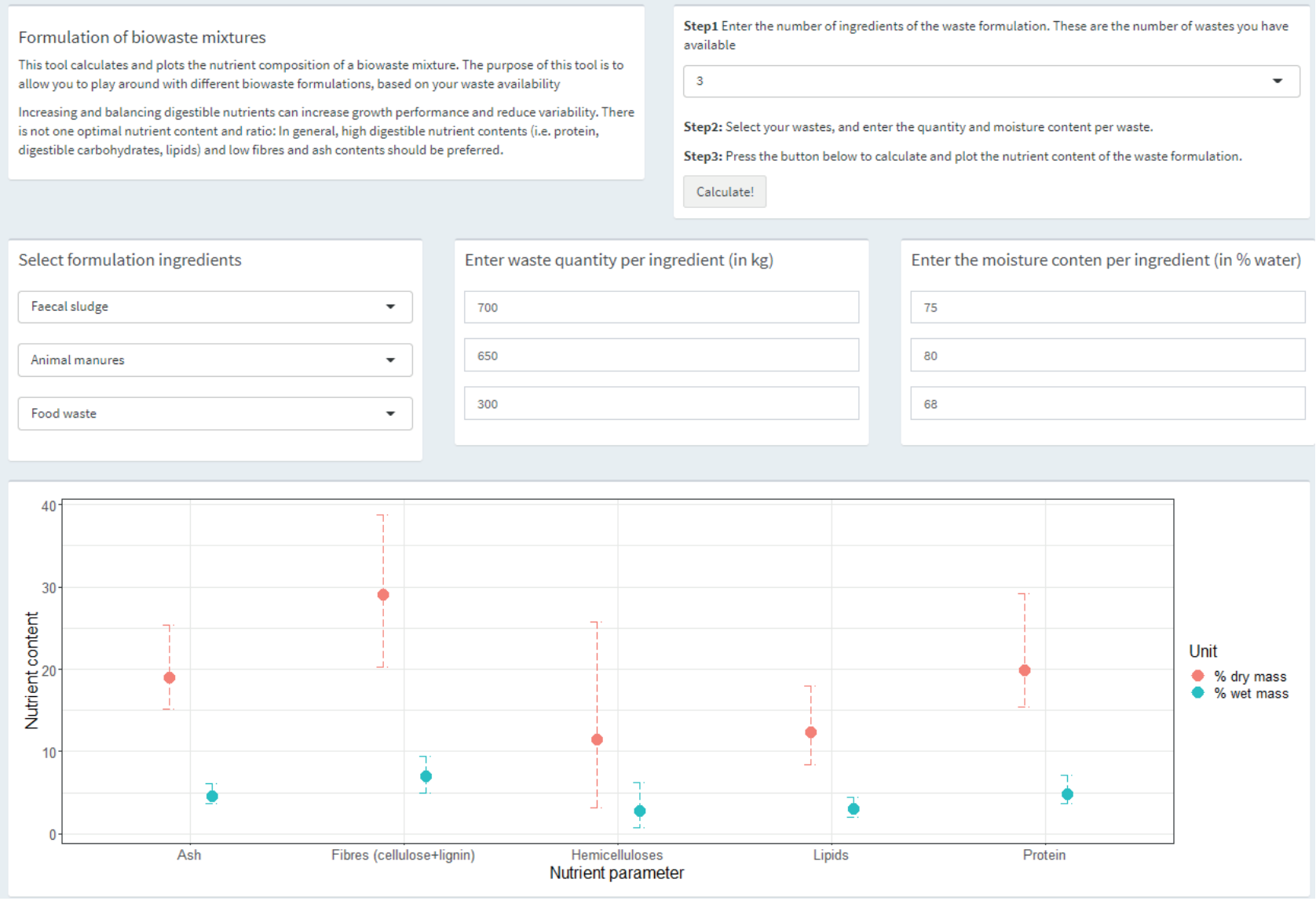

FIGURE 4: The "Substrate mixture formulation" tab of the web application calculates the nutrient composition of a biowaste mixture based on the substrate, quantity, and moisture content provided by the user. 
TABLE 2: Potential hazards in BSFL substrates. $A=$ mycotoxins, $B$ = human/veterinary drugs, $C=$ agricultural chemicals, $D=$ microbial pathogens and their toxins (e.g. Botulinum toxin), $\mathrm{E}=$ metals, and $\mathrm{F}=$ misfolded prion proteins (Bosch et al., 2017; FAO 1997; Gold et al. 2018; Lalander et al., 2016; Purschke et al., 2017).

\begin{tabular}{l:l}
\hline Waste & Hazard \\
\hline Human faeces and excreta & B, D \\
\hline Wastewater and faecal sludge & B, D, E \\
\hline Animal manure & B, C, D, E \\
\hline Slaughterhouse waste & D, F \\
\hline Household waste & D, E \\
\hline Cereal-based byproducts & A, D \\
\hline Food \& restaurant waste & A, D \\
\hline Food processing waste & A, D \\
\hline
\end{tabular}

Strategies aimed at these hazards to meet legal feed limits include the selection of traceable substrates with low contaminant concentrations, mixing of substrates with low and higher contaminant concentrations, a series of post-processing steps to reduce contamination levels, for example, pasteurization (EC, 2011) including good hygiene practices (IPIFF 2019). At the BSFL treatment facility in Nairobi, only human faeces collected from standardised and well operated source-separating toilets are used. Separation of faeces from urine means that an estimated twothirds of the excreted drug residues are disposed of elsewhere (Lienert et al., 2007). Furthermore, mixing faeces with sawdust in the toilet, and co-processing this mixture with dischared fruits and vegetables, that is, FFS, further reduces drug residue concentrations. Although not yet shown in the few completed studies, in cases where drug residues are carried over to BSFL, heat treatment contributes to their inactivation (Tian et al., 2017). All substrates identified in Nairobi may include microbial pathogens; therefore, live BSFL should not be fed to animals. Further research is needed to determine how the hazards in wastewater sludge, for example, heavy metals, and slaughterhouse waste, for example, misfolded prion proteins, can be managed.

\subsection{Waste recovery hierarchy}

BSFL treatment is frequently selected with the aim of providing biowaste treatment and products with lower environmental impact than the status quo (Mertenat et al., 2019; Smetana et al., 2019). To deliver this goal, the waste recovery hierarchy is a useful and established concept. It indicates the order of preferences of waste reduction and management measures. The order of most preferred to least preferred measures includes prevention, reduction, recycling, recovery, and disposal (UNEP, 2013). We propose to extend this concept to encompass the treatment of biowaste with BSFL (Figure 5). BSFL treatment should be the most preferred measure following waste prevention, for example, by strategies to avoid food waste, and waste reduction (including reuse), for example, by using animal feed. For this Nairobi case study, it means although cereal-based byproducts and some food and fruit/vegetable wastes have favorable nutrient content and process performance with BSFL they should not be diverted to BSFL treatment because of their potential use as animal feed and part in meaningful resource recovery. In addition, BSFL treatment should be considered before other waste treatment technologies, such as anaerobic digestion or composting, to recycle nutrients back into the food chain. Biowaste, for example from the food processing industry, can therefore, enter a circular value chain (Cappellozza et al., 2019).

\subsection{Trade-offs between selection criteria}

The present Nairobi case study has demonstrated that selecting substrates for BSFL treatment is a trade-off between larval biomass production efficiency and substrate costs, with overarching considerations for the safety and sustainability of the larval-based products. Substrates that have the highest performance typically have high costs and are already used as animal feed, and this concords with the waste hierarchy concept and circular economy principles. The remaining substrates that are available at reasonable costs have lower performances and require careful consideration to ensure product safety.

Based on the four-criteria assessment here, a mixture of human faeces, animal manure, fruit/vegetable waste, and food waste should be targetted for upscaling the BSFL treatment facility in Nairobi. Biowaste mixtures with similar nutrient contents can be calculated with the "Substrate mixture formulation" tab (Figure 4) of the web application. Multiplication or further expansion of the facility requires changes in Nairobi's waste management system, such as increased separation of biowaste from inorganic wastes and financially viable collection services. Seventy to eighty percent of Nairobi's biowaste is household waste mixed with inorganics, which makes it unsuitable for BSFL treatment (Kirai et al., 2009). Furthermore, only $30-50 \%$ of waste in Nairobi is collected (Aryampa et al., 2019; Kasozi \& Von Blottnitz, 2010). Achieving universal waste management services in Nairobi is challenging, particularly when considering that more than $50 \%$ of the population lives in informal areas.

All original data presented in this study is publicly available. The "BSFL Substrate Explorer" at the time of writing this paper can be downloaded at Eric/open (https://opendata.eawag.ch), the Eawag Research Data Institutional Repository (DOI: 10.25678/00051D). The current version can be found at https://github.com/MoritzGold/BSF_app.

\section{AKNOWLED GEMENTS}

This research was funded by the Sawiris Foundation for Social Development (Engineering for Development (E4D) Scholarship Program), Eawag, and supported by the ETH Zurich Foundation, ETH Global, and Bühler AG. The development of the web application would not have been possible without the encouragement and technical support of Lars Schöbitz (Lars Schöbitz GmbH).

\section{REFERENCES}

Aryampa, S., Maheshwari, B., Sabiiti, E., Bateganya, N. L., \& Bukenya, B. (2019). Status of waste management in the East African cities: Understanding the drivers of waste generation, collection and disposal and their impacts on Kampala City's sustainability. Sustainability, 11(19), 1-16. 


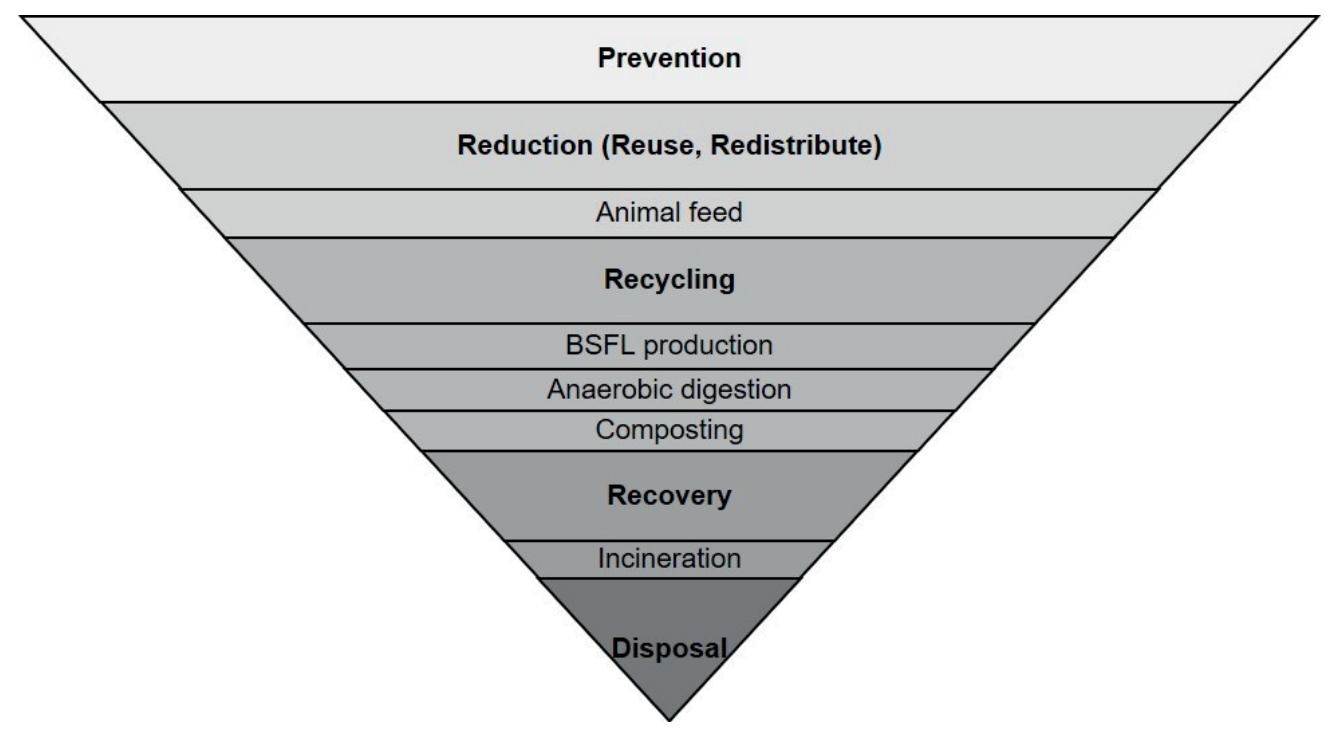

FIGURE 5: Biowaste recovery hierarchy including BSFL treatment. Adapted from Papargyropoulou et al. (2014) and UNEP (2013).

Banks, I. J., Gibson, W. T., \& Cameron, M. M. (2014). Growth rates of black soldier fly larvae fed on fresh human faeces and their implication for improving sanitation. Tropical Medicine and International Health, 19(1), 14-22.

Barragán-Fonseca, K. B., Dicke, M., \& van Loon, J. J. A. (2017). Nutritional value of the black soldier fly (Hermetia illucens L.) and its suitability as animal feed - a review. Journal of Insects as Food and Feed, 3(2), 105-120.

Barragán-Fonseca, K., Pineda-Mejia, J., Dicke, M., \& Van Loon, J. J. A. (2018). Performance of the Black Soldier Fly (Diptera: Stratiomyidae) on Vegetable Residue-Based Diets Formulated Based on Protein and Carbohydrate Contents. Journal of Economic Entomology, 111(6), 2676-2683.

Baud, I. S. A., Post, J., \& Furedy, C. (2004). Solid waste management and recycling: actors, partnerships and policies in Hyderabad, India and Nairobi, Kenya. Kluwer Academic Publishers.

Bava, L., Jucker, C., Gislon, G., Lupi, D., Savoldelli, S., Zucali, M., \& Colombini, S. (2019). Rearing of hermetia illucens on different organic by-products: Influence on growth, waste reduction, and environmental impact. Animals, 9(6), 289

Bosch, G., Fels-Klerx, H., Rijk, T., \& Oonincx, D. G. A. B. (2017). Aflatoxin B1 Tolerance and Accumulation in Black Soldier Fly Larvae (Hermetia illucens) and Yellow Mealworms (Tenebrio molitor). Toxins, 9(6), 185.

Bosch, G., van Zanten, H. H. E., Zamprogna, A., Veenenbos, M., Meijer, N. P., van der Fels-Klerx, H. J., \& van Loon, J. J. A. (2019). Conversion of organic resources by black soldier fly larvae: Legislation, efficiency and environmental impact. Journal of Cleaner Production, 222, 355-363.

Bosch, Guido, Zhang, S., G.A.B., D., \& Hendriks, W. H. (2014). Protein quality of insects as potential ingredients for dog and cat foods. Journal of Nutritional Science, 3(29), 1-4.

Chen, C., Chaudhary, A., \& Mathys, A. (2020). Nutritional and environmental losses embedded in global food waste. Resources, Conservation and Recycling, 160, 104912.

Chang, W., Cheng, J., Allaire, J., Xie, Y., \& McPherson, J. (2020). shiny: Web Application Framework for R. R package version 1.4.0.2. https://cran.r-project.org/package=shiny

Chang, W., \& Ribeiro, B. B. (2018). shinydashboard: Create Dashboards with "Shiny". R package version 0.7.1. https://cran.r-project.org/ package $=$ shinydashboard

Charlton, A. J. J., Dickinson, M., Wakefield, M. E., Fitches, E., Kenis, M., Han, R., Zhu, F., Kone, N., Grant, M., Koko, G., Devic, D., Bruggeman, G., Devic, E., Bruggeman, G., Prior, R., \& Smith, R. (2015). Exploring the chemical safety of fly larvae as a source of protein for animal feed Journal of Insects as Food and Feed, 1(1), 7-16.
Chen, X., Zhao, G., Zhang, Y., Han, L., \& Xiao, W. (2017). Nitrogen-to-protein conversion factors for crop residues and animal manure common in China. Journal of Agricultural and Food Chemistry, 65(42), 9186-9190.

Diener, S., Semiyaga, S., Niwagaba, C. B., Muspratt, A. M., Gning, J. B., Mbéguéré, M., Ennin, J. E., Zurbrügg, C., \& Strande, L. (2014). A value proposition: Resource recovery from faecal sludge - Can it be the driver for improved sanitation? Resources, Conservation and Recycling 88, 32-38.

Diener, S., Zurbrügg, C., Gutiérrez, F. R., Nguyen, D. H., Morel, A., Koottatep, T., \& Tockner, K. (2011). Black soldier fly lavae for organic waste treatment - prospects and constraints. 2nd International Conference on Solid Waste Management in Developing Countries, Khulna, Bangladesh, 52(February), 1-8.

Diener, S., Zurbrügg, C., Tockner, K. (2015). Bioaccumulation of heavy metals in the BSF, Hermetia illucens, and effects on its life cycle. Journal of Insects as Food and Feed, 1(4), 261-270.

Diener, Stefan, Zurbrügg, C., Tockner, K. (2009). Conversion of organic material by BSF larvae: establishing optimal feeding rates. Waste Management \& Research 27(6), 603-610.

Dieu, T. T. M., Thien, N. N., Hang, N. T. T., \& Chung, P. N. (2015). Possibility of degrading water hyacinth by black soldier larvae International Journal of Innovative Science, Engineering \& Technology, 2(2), 174-180.

Dortmans, B., Diener, S., Verstappen, B. M. \& Zurbrügg, C. (2017). Black soldier fly biowaste processing: A step-by-step guide. Swiss Federal Institute of Aquatic Science and Technology (Eawag).

Ermolaev, E., Lalander, C., Vinnerås, B. (2019). Greenhouse gas emissions from small-scale fly larvae composting with Hermetia illucens Waste Management, 96, 65-74.

European Commission (EC) (2011). Commission Regulation (EU) No 142/2011: Health rules regarding animal by-products and derived products not intended for human consumption. Official Journal of the European Union

Food and Agicultural Organization (FAO) (1997). Animal feeding and the safety of food (FAO Expert Consultation Report).

Giromini, C., Ottoboni, M., Tretola, M., Marchis, D., Gottardo, D., CapraruIo, V., Pinotti, L., Ottoboni, M., Tretola, M., Marchis, D., \& Gottardo, D. (2017). Food Additives \& Contaminants : Part A Nutritional evaluation of former food products (ex-food) intended for pig nutrition. Food additives \& contaminants: Part A, 34(8), 1436-1445.

Gold, M., Tomberlin, J. J. K., Diener, S., Zurbrügg, C., \& Mathys, A. (2018a). Decomposition of biowaste macronutrients, microbes, and chemicals in black soldier fly larval treatment: A review. Waste Management, 82, 302-318.

Gold, M., Spiess, R., Zurbrügg, C., Kreuzer, M., Mathys, A., 2018b. Digestibility of different dietary fibres by black soldier fly larvae. Bornimer Agrartech. Berichte 100. 
Gold, M., Cassar, C. M., Zurbrügg, C., Kreuzer, M., Boulos, S., Diener, S., \& Mathys, A. (2020a). Biowaste treatment with black soldier fly larvae: Increasing performance through the formulation of biowastes based on protein and carbohydrates. Waste Management, 102, 319-329.

Gold, M., von Allmen, F., Zurbrügg, C., Zhang, J., and Mathys, A. (2020b). Identification of bacteria in two food waste black soldier fly larvae rearing residues Frontiers in Microbiology, 11, 2897.

Gold, M., Fowles, T., Fernandez-Bayo, J. D., Palma Miner, L., Zurbrügg, C., Nansen, C., Bischel, H. N., Mathys, A. (2021). Effects of rearing system and microbial inoculation on black soldier fly larvae growth and microbiota when reared on agri-food by-products Journal of Insects as Food and Feed.

Gower \& Schröder, P. (2018). Cost-benefit assessment of community-based recycling and waste management in Pakistan

Gustavsson, J., Cederberg, C., Sonesson, U., van Otterdijk, R. \& Meybeck, A. (2011). Global Food Losses and Food Waste Extent, Causes, and Prevention.

Hoornweg D, Bhada-Tata P (2012). What a Waste. A global review of solid waste management. In Urban Development Series Knowledge Papers No. 15.

Isibika, A., Vinnerås, B., Kibazohi, O., Zurbrügg, C., Lalander, C. (2019). Pre-treatment of banana peel to improve composting by the BSF (Hermetia illucens (L.), Diptera : Stratiomyidae) larvae. Waste Management, 100, 151-160.

Ites S, Smetana S, Toepfl S, Heinz V (2020). Modularity of insect production and processing as a path to efficient and sustainable food waste treatment. Journal of Cleaner Production, 248. https://doi. org/10.1016/j.jclepro.2019.119248

Jucker, C., Erba, D., Leonardi, M. G., Lupi, D., Savoldelli, S. (2017). Assessment of vegetable and fruit substrates as potential rearing media for Hermetia illucens (Diptera: Stratiomyidae) larvae. Environmental Entomology, 46(6), 1415-1423.

Njoroge K, Kimani M, Ndunge D (2014). Review of Solid Waste Management: A Case Study of Nairobi. Research Inventy: International Journal of Engineering and Science, 4(2), 2319-6483.

Kasozi, A. \& Von Blottnitz, H. 2010. Solid Waste Management in Nairobi: A Situation Analysis

Kassambara, A. \& Mundt, F. (2020). factoextra: Extract and Visualise the Results of Multivariate Data Analyses. R package version 1.0.7. https://cran.r-project.org/package=factoextra

Kenyan Bureau of Standards (KEBS) (2019). 2019 Kenya Population and Housing Census.

Kirai, P., Gachugi, J. \& Scheinberg, A. (2009). Converting City Waste Into Compost: Pilot Nairobi: Phase one - Inventory and Assessment.

Lalander, C., Diener, S., Zurbrügg, C., Vinnerås, B. (2019). Effects of feedstock on larval development and process efficiency in waste treatment with BSF (Hermetia illucens). Journal of Cleaner Production, 208, 211-219.

Lalander, C., Senecal, J., Gros Calvo, M., Ahrens, L., Josefsson, S., Wiberg, K., Vinnerås, B., 2016. Fate of pharmaceuticals and pesticides in fly larvae composting Science of the Total Environment, $565,279-286$

Le, S., Josse, J., Husson, F. (2008). FactoMineR: An R package for multivariate analysis. J Statistical Software, 25(1), 1-8.

Liu, Z., Minor, M., Morel, P. C. H., \& Najar-rodriguez, A. J. (2018). Bioconversion of three organic wastes by black soldier fly (Diptera: Stratiomyidae) larvae. Environmental Entomology, 47(6), 1609-1617.

Lohri, C. R., Faraji, A., Ephata, E., Rajabu, H. M., \& Zurbrügg, C. (2015). Urban biowaste for solid fuel production : Waste suitability assessment and experimental carbonisation in Dar es. Waste Management \& Research, 33(2), 175-182.

Makkar, H. P. S., Tran, G., Heuzé, V., \& Ankers, P. (2014). State-of-the-art on use of insects as animal feed Animal Feed Science and Technology, 197, 1-33.

Mariotti, F., Tomé, D., Mirand, P. P. (2008). Converting nitrogen into protein Beyond 6.25 and Jones' factors. Critical Reviews in Food Science and Nutrition, 48(2), 177-184.

Mazza, L., Xiao, X., ur Rehman, K., Cai, M., Zhang, D., Fasulo, S., Tomberlin, J. K., Zheng, L., Soomro, A. A., Yu, Z., \& Zhang, J. (2020). Management of chicken manure using black soldier fly (Diptera: Stratiomyidae) larvae assisted by companion bacteria. Waste Management, 102, 312-318.

Meneguz, M., Schiavone, A., Gai, F., Dama, A., Lussiana, C., Gasco, L. (2018). Effect of rearing substrate on growth performance, waste reduction efficiency, and chemical composition of black soldier fly (Hermetia illucens) larvae. Journal of the Science of Food and Agriculture, 98, 5776-5784
Mertenat, A., Diener, S., \& Zurbrügg, C. (2019). Black Soldier Fly biowaste treatment: Assessment of global warming potential. Waste Management, 84, 173-181.

Miranda, C. D., Cammack, J. A., \& Tomberlin, J. K. (2019). Life-history traits of the BSF, Hermetia illucens (L.) (Diptera: Stratiomyidae) reared on three manure types. Animals, 9(5).

Nguyen, T. T. X., Tomberlin, J. K., and Vanlaerhoven, S. 2013. Influence of Resources on Hermetia illucens (Diptera: Stratiomyidae) Larval Development. J. Med. Entomol, 50(4), 898-906.

Nyakeri, E. M., Ayieko, M.A., Amimo, F. A., Salum, H., \& Ogola, H. J. O. (2019). An optimal feeding strategy for black soldier fly larvae biomass production and faecal sludge reduction. Journal of Insects as Food and Feed, 1(1), 1-14.

Purschke, B., Scheibelberger, R., Axmann, S., Adler, A., and Jäger, H. 2017. Impact of substrate contamination with mycotoxins, heavy metals, and pesticides on growth performance and composition of black soldier fly larvae (Hermetia illucens) for use in the feed and food value chain. Food additives \& contaminants: Part A, 34(8), $1410-1420$.

R Core Team. (2020). R: A language and environment for statistical computing. https://www.r-project.org/

Rehman, K. ur, Rehman, A., Cai, M., Zheng, L., Xiao, X., Somroo, A. A. Wang, H., Li, W., Yu, Z., \& Zhang, J. (2017). Conversion of mixtures of dairy manure and soybean curd residue by BSF larvae (Hermetia illucens L.). Journal of Cleaner Production, 154, 366-373.

Rehman, K. ur, Ur Rehman, R., Somroo, A. A., Cai, M., Zheng, L., Xiao, X., Rehman, A., Rehman, A., Tomberlin, J. K., Yu, Z., \& Zhang, J. (2019). Enhanced bioconversion of dairy and chicken manure by the interaction of exogenous bacteria and BSF larvae. Journal of Environmental Management, 237(February), 75-83.

Schmitt, E., Belghit, I., Johansen, J., Leushuis, R., Lock, E. J., Melsen, D., Ramasamy Shanmugam, R. K., Loon, J. Van, \& Paul, A. (2019). Growth and safety assessment of feed streams for BSF larvae: A case study with aquaculture sludge. Animals, 9(4), 189.

Shumo, M., Osuga, I. M., Khamis, F. M., Tanga, C. M., Fiaboe, K. K. M., Subramanian, S., Ekesi, S., van Huis, A., \& Borgemeister, C. (2019). The nutritive value of BSF larvae reared on common organic waste streams in Kenya. Scientific Reports, 9(1), 1-13.

Smetana, S., Palanisamy, M., Mathys, A., Heinz, V., 2016. Sustainability of insect use for feed and food: Life Cycle Assessment perspective. J. Clean. Prod., 137, 741-751.

Smetana, S., Schmitt, E. \& Mathys, A. (2019). Sustainable use of Hermetia illucens insect biomass for feed and food: Attributional and consequential life cycle assessment. Resources, Conservation and Recycling, 144, 285-296.

Somroo, A. A., ur Rehman, K., Zheng, L., Cai, M., Xiao, X., Hu, S., Mathys, A., Gold, M., Yu, Z., \& Zhang, J. (2019). Influence of Lactobacillus buchneri on soybean curd residue co-conversion by black soldier fly larvae (Hermetia illucens) for food and feedstock production. Waste Management, 86, 114-122.

Spranghers, T., Ottoboni, M., Klootwijk, C., Ovyn, A., Deboosere, S., De Meulenaer, B., Michiels, J., Eeckhout, M., De Clercq, P. \& De Smet, S. (2017). Nutritional composition of black soldier fly (Hermetia illucens) prepupae reared on different organic waste substrates Journal of the Science of Food and Agriculture, 97(8), 2594-2600.

Sriperm, N., Pesti, G. M., \& Tillman, P. B. (2011). Evaluation of the fixed nitrogen-to-protein $(N: P)$ conversion factor (6.25) versus ingredient specific N:P conversion factors in feedstuffs. Journal of the Science of Food and Agriculture, 91(7), 1182-1186.

Tschirner, M. \& Simon, A. 2015. Influence of different growing substrates and processing on the nutrient composition of black soldier fly larvae destined for animal feed Journal of Insects as Food and Feed, 1(4), 249-259.

United Nations Development Program (UNEP). (2013). Guidelines for National Waste Management Strategies: Moving from Challenges to Opportunities

Van der Fels-Klerx, H. J., Camenzuli, L., Belluco, S., Meijer, N., \& Ricci, A. (2018). Food Safety Issues Related to the Uses of Insects for Feeds and Foods Comprehensive Reviews in Food Science and Food Safety, 17, 1172-1183

van der Fels-Klerx, H. J., Meijer, N., Nijkamp, M. M., Schmitt, E., \& van Loon, J. J. A. (2020). Chemical food safety of using former foodstuffs for rearing black soldier fly larvae (Hermetia illucens) for feed and food use. Journal of Insects as Food and Feed, 6(5), 475-488. 
Vruggink, M. (2020). Protein-rich animal feed: Development of an Assessment Framework for Black Soldier Fly Larvae Substrate Suitability Master thesis École Polytechnique Fédérale de Lausanne (EPFL).

Wickham et al. (2019) Welcome to the tidyverse. Journal of Open Source Software, 4(43).

Wickham, H. (2016). ggplot2: Elegant Graphics for Data Analysis. Springer-Verlag.

Wilson, D. C., Rodic, L., Modak, P., Soos, R., Carpintero, A., Velis, K., lyer, M., \& Simonett, O. 2015. Global waste management outlook

Zurbrügg, C., Dortmans, B., Fadhila, A., Verstappen, B., Diener, S., 2018. From Pilot to Full-Scale Operation of a Waste-To-Protein Treatment Facility. Detritus, 1, 18-22. 